\title{
Early Strength Development of Soft Clay Stabilized by One-Part Ground Granulated Blast Furnace Slag and Fly Ash-Based Geopolymer
}

\author{
Xiyao Zheng and Jun $W u$ * \\ School of Urban Railway Transportation, Shanghai University of Engineering Science, Shanghai, China
}

OPEN ACCESS

Edited by:

Guangming Chen,

South China University of Technology,

China

Reviewed by:

Ping Duan,

China University of Geosciences

Wuhan, China

Jiangxiong Wei,

South China University of Technology,

China

*Correspondence:

Jun Wu

cvewujun@163.com

Specialty section:

This article was submitted to

Structural Materials,

a section of the journal

Frontiers in Materials

Received: 12 October 2020

Accepted: 08 February 2021

Published: 16 April 2021

Citation:

Zheng X and Wu J (2021) Early Strength Development of Soft Clay

Stabilized by One-Part Ground Granulated Blast Furnace Slag and Fly

Ash-Based Geopolymer.

Front. Mater. 8:616430.

doi: 10.3389/fmats.2021.616430
One-part or "just add water" geopolymer is a cementitious material, which is friendly to environment and users in applications. However, the mechanical behavior of the soft soil stabilized by one-part geopolymer is not well acknowledged. In this study, soft clay was stabilized with ground granulated blast furnace slag (GGBFS) and fly ash (FA)-based geopolymer, which is a mixture of solid aluminosilicate precursor (Al-Si raw materials: GGBFS and FA), solid alkali activator, and water. The objective was to adopt one-part geopolymer as an alternative soil binder to completely replace ordinary Portland cement (OPC) for stabilizing the soft clay and evaluate the effect of the factors (i.e., GBFS/FA ratio in Al-Si precursor, activator/Al-Si precursor ratio, and water/binder ratio) that influenced the early strength. Results showed that the increase of the FA content in the Al-Si precursor increased the unconfined compressive strength (UCS) values significantly through the geopolymerization process. The highest UCS values were achieved with 90\% GGBFS to $10 \% \mathrm{FA}$ in the precursor when the activator/precursor and water/binder ratio is 0.15 and 0.7 , respectively. The UCS values of geopolymer-stabilized clay could reach $1.5 \mathrm{MPa}$ at 14 days at ambient temperature, which is much higher than that of OPC-stabilized clay. The microstructure and mineralogy analyses indicated that the prolific hydration products, such as calcium silicate hydrate (C-S-H), calcium aluminum hydrate (C-A-H), and calcium aluminum silicate hydrate (C-A-S-H), contributed greatly to strengthen the soft clay by forming the soil skeleton and infilling among clay particles, while sodium aluminosilicate (N-A-S-H) gel is only served to fill the part of porosities in the soil and cannot effectively enhance the UCS of the one-part geopolymer-stabilized soft clay. This paper results suggested that one-part GGBFS-FA-based geopolymers have the potential to replace OPC in the manufacture of stabilized soft clay.

Keywords: one-part geopolymer, ground granulated blast furnace slag, fly ash, microstructure, hydration

\section{INTRODUCTION}

Geopolymer is an alternative binder agent that belongs to a new type of cementitious material, which is polymerized from $\mathrm{Al}-\mathrm{Si}$ raw materials. The $\mathrm{Al}-\mathrm{Si}$ raw materials are usually available from low-cost industrial by-products such as ground granulated blast furnace slag (GGBFS) and fly ash (FA). With the activation of alkali-activator, the $\mathrm{Al}-\mathrm{Si}$ raw materials produce hydration materials with the characteristics of high early strength. In geotechnical engineering, the ordinary Portland cement 
(OPC) is normally used as a soil stabilizer to improve soil with poor mechanical properties (Keshawarz and Dutta, 1993; Taha et al., 2002; Horpibulsuk et al., 2006; Chinkulkijniwat et al., 2012; Du et al., 2013; Ma et al., 2018). However, it is well known that the OPC consumes a lot of energy resources and emits a lot of $\mathrm{CO}_{2}$ gases, causing environmental pollutions in the production process (Davidovits, 1991; Bakharev et al., 2001a; Bakharev et al., 2001b; Huntzinger and Eatmon, 2009). At the same time, the OPC-stabilized soft clay often has the problem of insufficient early strength. Since the Al-Si raw materials of the geopolymer came from industrial by-products with the lower cost compared to OPC, adopting the geopolymer as the binder agent to stabilize the soil had a great potential to solve the " $3 \mathrm{H}$ " problems (high pollution, high energy consumption, and high cost) induced by the application of OPC binder. Furthermore, the early strength development of geopolymer paste was faster than that of OPC paste, which might enhance the early strength of stabilized soil and shorten the constriction time.

In recent years, the application of geopolymers in the stabilized soil has been widely studied. Cristelo et al. (2011) investigated the mechanical strength of FA-based geopolymerstabilized soft soil with the sodium-based alkali activators and found that the unconfined compressive strength (UCS) values of FA-based geopolymer-stabilized soft soil increased to $900 \mathrm{kPa}$ compared to untreated soil with the initial strength of $100 \mathrm{kPa}$. Zhang et al. (2013) adopted the metakaolin-based geopolymer to stabilize the soil at shallow depth. It was found that the geopolymer gel could help soil particles form dense microstructures and improve the original strength of the soil significantly. Itthikorn et al. (2018) used the FA and GGBFS as Al-Si raw materials and liquid alkali as the activator to stabilize the base layer in pavement engineering. The effects of GGBFS, the molarity of the liquid alkali activator, and curing time on the early strength development of the stabilized soil were investigated. It was reported that at sevendays, the UCS values of the geopolymer-stabilized soil achieved $7 \mathrm{MPa}$. The scanning electron microscope (SEM) results indicated that the calcium silicate hydrate (C-S-H) and sodium aluminosilicate hydrate (N-A-S-H) products were formed in the geopolymerstabilized soil.

However, the above application of geopolymers in the stabilized soil usually adopted the two-part geopolymer technology. As for the two-part geopolymer, a liquid alkali activator was first prepared by a mixture of sodium hydroxide $(\mathrm{NaOH}, \mathrm{NH})$ solution and sodium silicate $\left(\mathrm{Na}_{2} \mathrm{SiO}_{3}, \mathrm{NS}\right)$ solution with certain $\mathrm{Al} / \mathrm{Si}$ molar ratio (Duxson et al., 2007; Provis and John, 2014). The liquid alkali activator was then added to the silicoaluminate raw material to synthesize the geopolymer paste. Finally, the geopolymer paste was used as a binder agent to stabilize the soil. In the practice of soil improvement, the deep cement mixing and the jet grouting were the main techniques to enhance the strength and stiffness of the soft soil at varied depths. In the jet grouting technique, the OPC and water were prepared within different pipes. After the drilling bit reached the soft soil at a certain depth, the OPC paste formed by the mixing of OPC and water with certain ratio would fill into an in situ soil layer. However, adopting alkaline solutions limits the commercial application of the two-part technology since it is difficult to handle these viscous, corrosive solutions in the construction site. The traditional two-part technology has some problems, such as high transportation cost and environmental protection. Thus, it is urgent to develop a new kind of geopolymer that could be used similarly to OPC. As for the one-part geopolymer, the alkali activator is prepared in the form of solid particles. It is expected that only a dry mixture would be needed in addition to water if the geopolymer was adopted for in situ ground improvement. Solid alkali activators can be more convenient in transportation and lower the price of transport costs. At the same time, solid alkali activators can reduce the harm of alkaline activator solution.

The major difference between two- and one-part geopolymers was the reactive rate and the availability of $\mathrm{Si}$, $\mathrm{Al}$, and $\mathrm{Ca}$ in source materials, which influenced the strength and microstructure development of geopolymers. Hence, the solid Al-Si materials were usually adopted in one-part geopolymers (Zhang et al., 2013). Research has been carried out to synthesize one-part geopolymers using a combination of different kinds of solid Al-Si raw materials and solid alkali activators. The common solid Al-Si raw materials adopted in one-part geopolymer mixes were FA and GGBFS (Nematollahi et al., 2017a; Nematollahi et al., 2017b; Wang et al., 2017). Since the high-calcium FA (defined as the ASTM class C FA) had the drawback of too rapid setting (Chindaprasirt et al., 2012), the low calcium FA (known as the ASTM class F FA) was the majority of FA used in one-part geopolymers. The GGBFS was seemed as a calcium-rich Al-Si raw material and commonly used with class F FA in the one-part geopolymer mixtures (Kim et al., 2013). It was found that adopting GGBFS in source materials can significantly promote the reactivity of low calcium content in FA during the synthesizing process of geopolymers (Duxson and Provis, 2008; Bondar et al., 2019). Alkali activators adopted in one-part geopolymer mixtures are mainly solid $\mathrm{NH}$ (or NS, $\mathrm{Na}_{2} \mathrm{CO}_{3}, \mathrm{NaAlO}_{2}$, and $\mathrm{KOH}$ ) (Nematollahi et al., 2017a; Nematollahi et al., 2017b). It was observed that the modulus (i.e., Si/Na molar ratio) of activators had impacts on the settling time and strength of the geopolymer paste significantly (Nematollahi et al., 2015; Wang et al., 2017). The main binding phases of one-part alkaliactivated geopolymers were found to be amorphous $\mathrm{C}-\mathrm{S}-\mathrm{H}$, calcium aluminate hydrates (C-A-H), and calcium aluminosilicate hydrates (C-A-S-H) gels (Gluth et al., 2013; Venkatanarayanan and Rangaraju, 2013; Sturm et al., 2015; Sturm et al., 2016a; Sturm et al., 2016b; Peys et al., 2016), which were similar to what generated in two-part geopolymers in the high-calcium system. These hydrate gels were the main contributors to enhance the strength of geopolymers. In addition, these hydrate gels can play an important role in the cementation between soil particles, which leads to the improvement of soil strength. Therefore, it is very promising to adopt the one-part geopolymer as a novel binder to stabilize soft soil. However, to the best of the author's knowledge, there are no published studies investigating the feasibility of the one-part geopolymer as a 
TABLE 1 | Basic properties of the soil used in the current study.

\section{Properties}

Liquid limit, LL (\%)

Plastic limit, PL (\%)

Plasticity index, PI (\%)

In situ water content, $w(\%)$

Initial void ratio, $e_{0}$

Specific gravity, $G_{S}$

Total unit weight, $r_{\mathrm{b}}\left(\mathrm{kN} / \mathrm{m}^{3}\right)$

In situ shear strength $(\mathrm{kPa})$
TABLE 2 | Chemical compositions of soil, GGBFS, and FA from XRF analysis (\%).

\begin{tabular}{lccccccc} 
& $\mathbf{M g O}$ & $\mathbf{A l}_{\mathbf{2}} \mathbf{O}_{\mathbf{3}}$ & $\mathbf{S i O}_{\mathbf{2}}$ & $\mathbf{C a O}$ & $\mathbf{T i O}_{\mathbf{2}}$ & $\mathbf{P}_{\mathbf{2}} \mathbf{O}_{\mathbf{5}}$ & $\mathbf{K}_{\mathbf{2}} \mathbf{O}$ \\
\hline Soil & 2.56 & 15.9 & 56.8 & 4.99 & 1.20 & 0.177 & 3.84 \\
GGBFS & 7.63 & 0.81 & 37.29 & 53.01 & 0.34 & 0.43 & - \\
FA & 0.68 & 29.46 & 56.38 & 2.76 & 2.76 & - & 1.53
\end{tabular}

The outcome of this paper would enable one-part GGBFS and FA-based geopolymers to be used as alternative binders to OPC in soil improvement.

\section{MATERIALS AND METHODS}

\section{Materials}

The soil sample used in the current study was the silt clay taken from the construction site at a depth of $12 \mathrm{~m}$ in Putuo district of Shanghai, China. The basic physical and mechanical properties of the soil are reported in Table $\mathbf{1}$. In addition, the particle size distribution curves of soil are given in Figure 1. The chemical composition of soil obtained from X-ray fluorescence spectroscopy (XRF) is given in Table 2. The undrained shear strength of this type of soil was about $20 \mathrm{kPa}$, which was too weak to support the proposed construction. Therefore, this soil was selected to be stabilized by one-part geopolymers in the current study.

GGBFS adopted in the current study was obtained from Suqian Huayi Concrete Co., Ltd., from Jiangsu Province, China. The chemical composition of GGBFS obtained from

were conducted to investigate the development microstructure of the one-part geopolymer-stabilized soil.

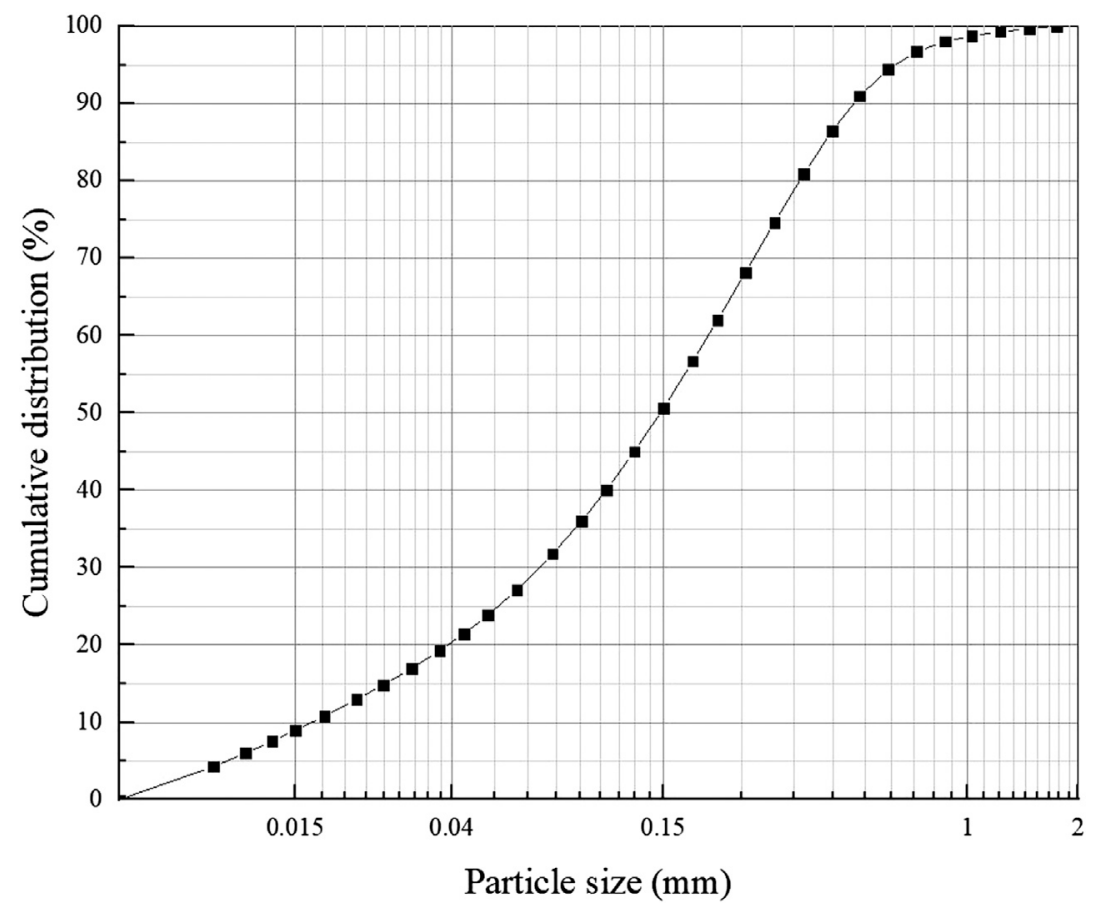

FIGURE 1 | Particle size distribution curves of soil. 


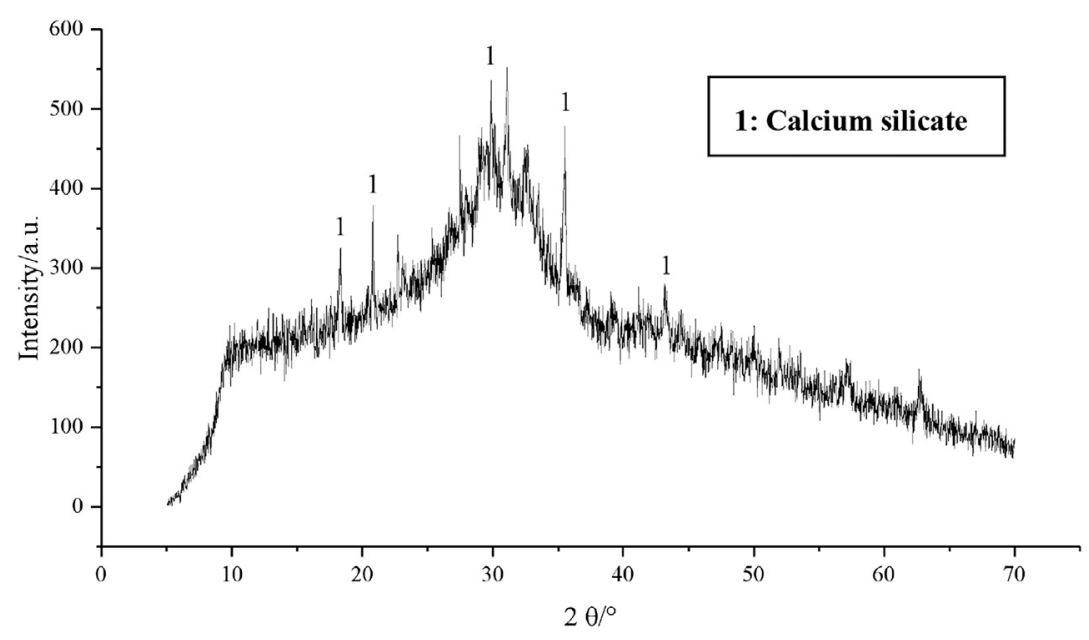

FIGURE 2 | XRD pattern of GGBFS in the current study.

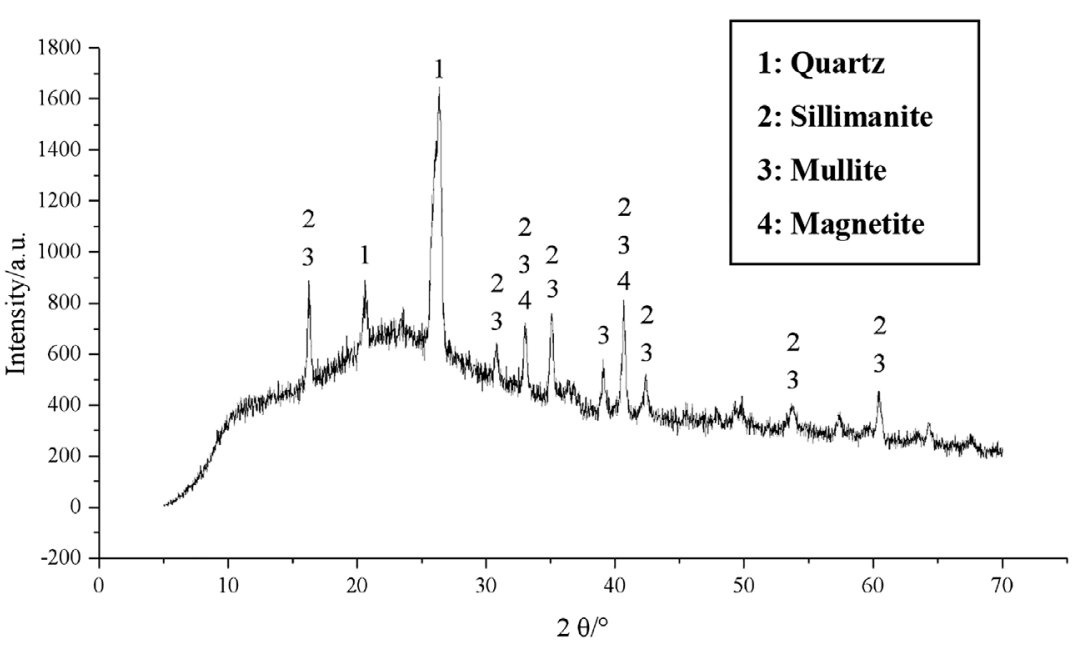

FIGURE 3 | XRD pattern of FA in the current study.

$\mathrm{XRF}$ is given in Table 2. The main chemical composition in the current GGBFS is $\mathrm{CaO}, \mathrm{SiO}_{2}$, and $\mathrm{MgO}$. The XRD pattern indicates that GGBFS mainly has the trace of calcium silicate in which the amorphous humps were in the region of $20^{\circ}-45^{\circ}$, as shown in Figure 2. FA was supplied from a power plant in Jiangyin City, Jiangsu Province, China. Table 2 reports the chemical composition of FA obtained from XRF. Hence, the FA in the current study was classified as a low calcium class F FA. The XRD pattern of FA is given in Figure 3. The alkali activator used in this paper was commercially available solid $\mathrm{NH}$ particles with a purity of $99 \%$. In addition, the particle size distribution curves of GGBFS and FA are shown in Figure 4.

\section{Sample Preparation}

After being placed in an oven drying for $24 \mathrm{~h}$, the raw soil was sieved through a $5 \mathrm{~mm}$ sieve to prepare a remolded specimen. The water content used in the remolded soil was $50 \%$, which was the soft clay's natural in situ water content. The procedure for preparing the one-part geopolymer-stabilized soil sample was similar to that cement-stabilized soil (Chew et al., 2004). The prescribed amount of water was first added into the dry soil particles to form clay-slurry. Binder (solid aluminosilicate precursor and solid alkali activator)-slurry was obtained through mixing with a certain water-binder ratio and was then added to clay-slurry to achieve the uniform mixing in the stabilized soil sample. All mixing was done within $45 \mathrm{~min}$ to avoid hardening of the soft clay-geopolymer mixture. The mixture was then placed into a PVC mold with a dimension of $39.8 \mathrm{~mm}$ in diameter and $80 \mathrm{~mm}$ height until the UCS test. In the laboratory test (Palomoa et al., 1999; Bakharev, 2006), the prepared geopolymer-stabilized soil samples were sealed with a plastic sheet and cured at a room temperature of $21 \pm 2^{\circ} \mathrm{C}$ with a 


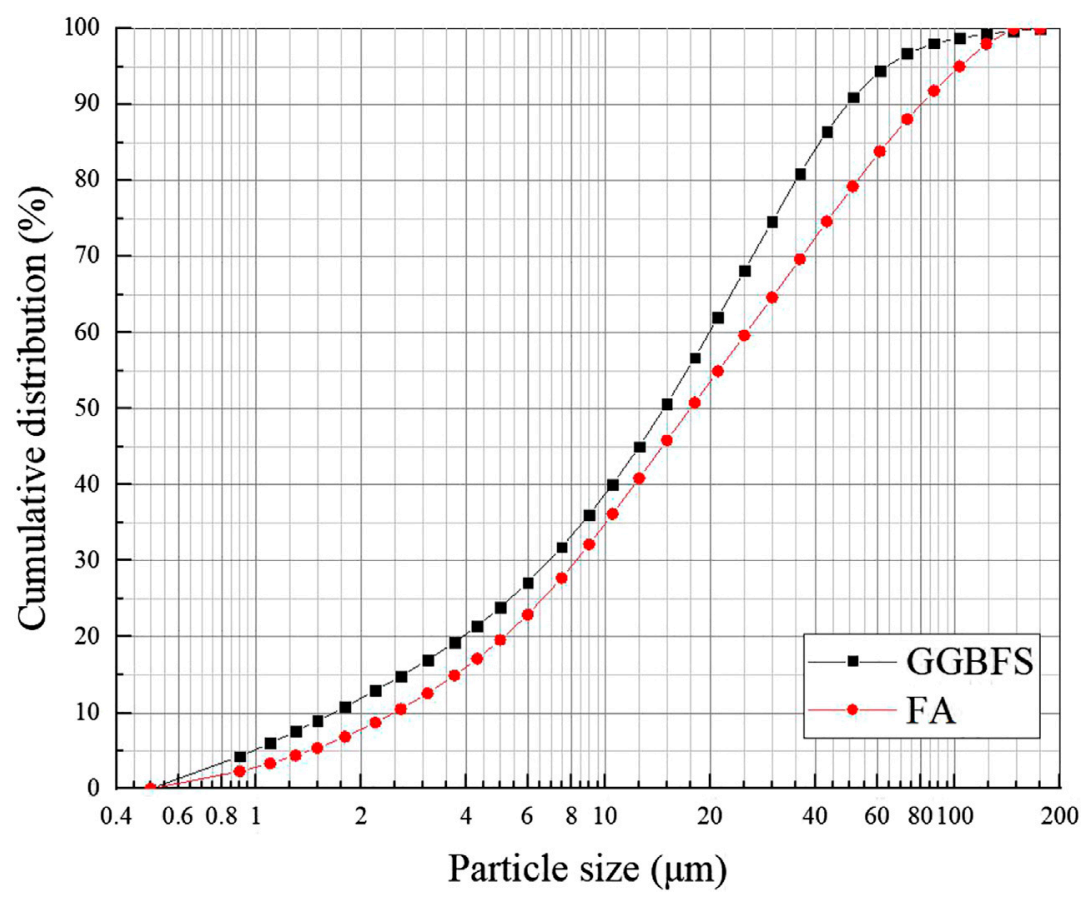

FIGURE 4 | Particle size distribution curves of GGBFS and FA.

relative humidity of $95 \%$. After $24 \mathrm{~h}$, the samples were demolded and then immediately wrapped in a plastic sheet and cured under the same condition as the abovementioned curing condition.

After completing the preparation of the sample, the UCS test of the one-part geopolymer-stabilized soil samples was conducted after 3,7 , and 14 days' curing time to investigate the early strength development. To study the development of microstructure in the one-part geopolymer-stabilized soil samples, the SEM analysis was performed on selected samples. In order to investigate the chemical compositions of the formed hydration products in the geopolymer-stabilized soft clay, the EDS test was conducted on the selected areas of SEM samples. The XRD was also carried out on the broken samples after UCS tests to observe the mineralogical changes in the one-part geopolymer-stabilized soft clay.

The cement-stabilized soil was set as the baseline test for comparison. The cement binder was the OPC with a grade of 42.5. The soil was the same as that used in one-part geopolymerstabilized soft clay. After curing times of 3, 7, and 14 days, the UCS values of the cement-stabilized soft soil were tested and then compared to that of one-part geopolymer-stabilized soft clay.

\section{Test Design}

According to the previous research on OPC-stabilized soft clay (Keshawarz and Dutta, 1993; Taha et al., 2002; Horpibulsuk et al., 2006; Chinkulkijniwat et al., 2012; Du et al., 2013; Kang et al., 2016), the optimum proportion of the binder in the cementstabilized soft clay was suggested to be in the range of $20-60 \%$ (binder to dry soil mass). In order to highlight the advantage of the one-part geopolymer stabilizer over the OPC binder in the

\begin{tabular}{lcccc}
$\begin{array}{l}\text { TABLE 3 } \\
\text { Mix no }\end{array}$ & Gixing proportion of samples in the current study (by mass). \\
\hline & & $\begin{array}{c}\text { NH: } \\
\text { Al-Si raw material }\end{array}$ & Water: binder & Molarity \\
\hline 1 & $100: 0$ & 0.1 & 0.7 & \\
2 & & 0.15 & 0.7 & 3.27 \\
3 & 0.15 & 0.6 & 5.64 \\
4 & 0.15 & 0.5 & 6.5 \\
5 & & 0.2 & 0.5 & 8.33 \\
6 & 0.1 & 0.7 & 3.27 \\
7 & $90: 10$ & 0.15 & 0.7 & 4.64 \\
8 & & 0.15 & 0.6 & 5.42 \\
9 & & 0.15 & 0.5 & 6.5 \\
10 & 0.2 & 0.5 & 8.33 \\
11 & & 0.1 & 0.7 & 3.27 \\
12 & $80: 20$ & 0.15 & 0.7 & 4.64 \\
13 & & 0.15 & 0.6 & 5.42 \\
14 & & 0.15 & 0.5 & 6.5 \\
15 & 0.2 & 0.5 & 8.33
\end{tabular}

application of ground improvement, the ratio between the binder and dry soil mass remained at $20 \%$ for both soil stabilizers. For the geopolymer binder in the current study, the binder was composed of raw materials (GGBFS and FA) and solid $\mathrm{NH}$ activator. The factors were considered as follows: the ratio of GGBFS to FA in the solid aluminosilicate precursor, the ratio of the solid $\mathrm{NH}$ activator to the precursor, and the ratio of the water to binder. Table 3 summarizes the samples with consideration of the above three factors. In the test, each design mixture is used in three samples to eliminate the sample error and ensure the accuracy of the test results. 

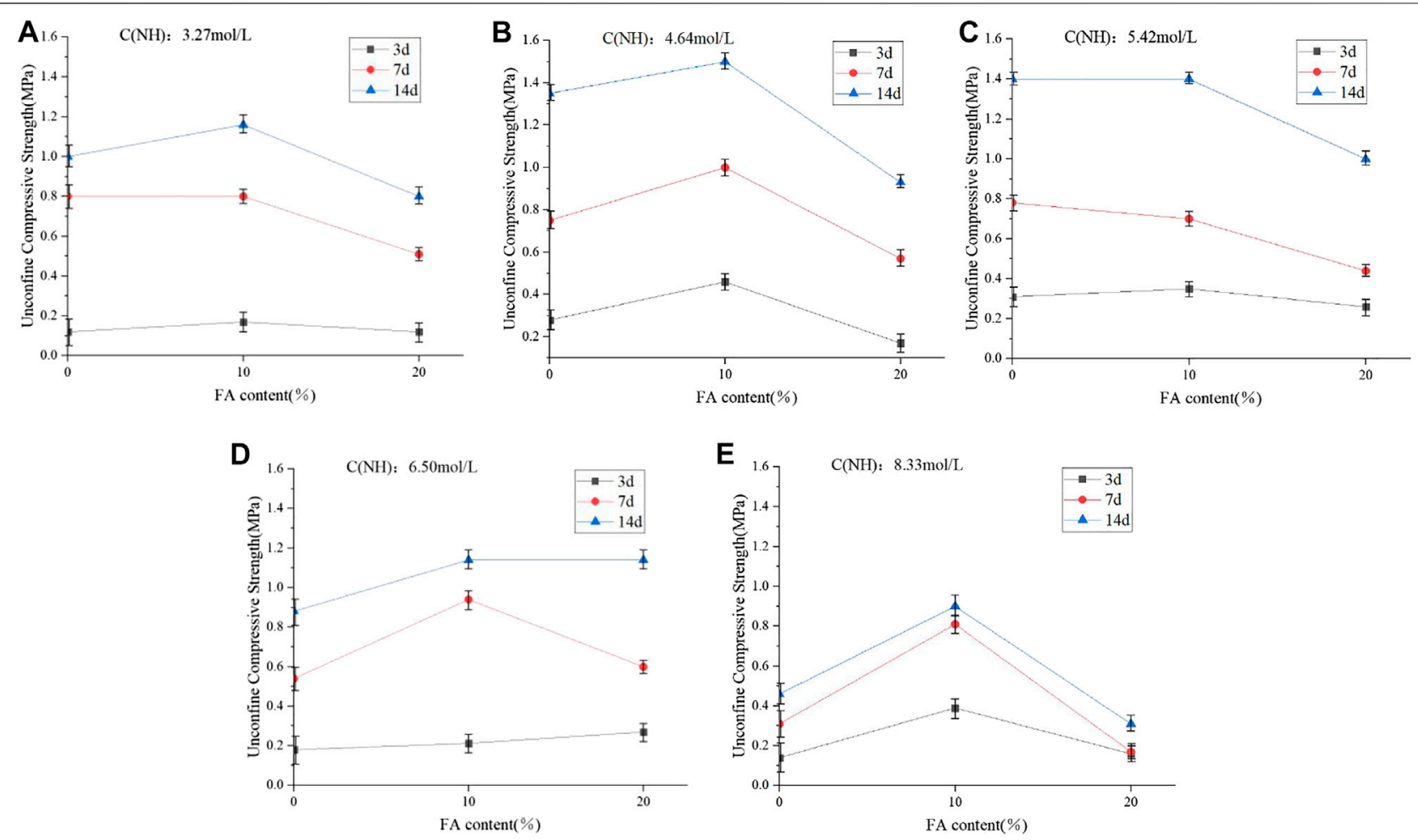

FIGURE 5 | UCS results of the one-part GGBFS-FA-based geopolymer-stabilized soil with different ratios of GGBFS to FA in the aluminosilicate raw material.

However, for the analysis purpose, the ratio of $\mathrm{NH}$ to raw materials and the water-to-binder ratio can be combined to the factor of molality of the alkali activator similar to that in two-part geopolymers (Glukhovsky et al., 1980; Bakharev et al., 1999). In the current study, the ratio of $\mathrm{NH}$ to raw and the water to binder ratio can be expressed in terms of molality of $\mathrm{NH}$ solution as follows:

$$
C(\mathrm{NH})=\frac{n(\mathrm{~mol})}{v(l)}=\frac{m_{\mathrm{NH}} / M_{\mathrm{NH}}}{m_{W} / \rho_{W}},
$$

in which $C(\mathrm{NH})$ is defined as the molarity of $\mathrm{NH}$ solution, $n$ represents the amount of substance, $v$ represents the volume of alkaline solution, $m_{\mathrm{NH}}$ is the mass of $\mathrm{NH}, m_{\mathrm{W}}$ is the mass of water, $M_{\mathrm{NH}}$ represents the molar mass of $\mathrm{NH}$, and $\rho_{\mathrm{W}}$ refers to the density of water.

\section{RESULTS AND DISCUSSION}

\section{Effect of Ground Granulated Blast Furnace Slag to Fly Ash Ratio in Raw Material}

The UCS values of one-part GGBFS and FA-based geopolymer-stabilized soft soil with different ratios of GGBFS to FA in raw materials are reported in Figure 5. It is clearly shown that the strength of geopolymer-stabilized soft soil increased with an increase in curing time. Therefore, it can be expected that geopolymers can play a role in improving the strength of soft soil and prove the feasibility that the current one-part geopolymer binder can be used to stabilize the soft soil.

For the mixing proportions with $100 \%$ GGBFS in the precursor, the UCS values of the stabilized soil were increased for the varied molalities of $\mathrm{NH}$ solution. When the FA content was less than $10 \%$, the UCS values of one-part geopolymerstabilized soil increased with an increase in the FA content; while for the FA content being more than 10\%, further increasing FA content would decrease the UCS values of the stabilized soft soil. This means that the highest UCS values of the one-part geopolymer-stabilized soil were achieved when the FA content was about $10 \%$ in raw materials. Excessive amount of FA had a negative impact on the strength development of the stabilized soil.

This phenomenon might be explained as follows. The siliconrich and calcium-rich components in the GGBFS released a large amount of silicate and calcium ions under the action of $\mathrm{NH}$ activator, and then these ions would react with each other to form the calcium silicate hydrates (C-S-H), which were used to connect the soil particles and enhance the UCS values of the stabilized soil. When the FA content was less than 10\%, a little FA was partially involved in the hydration reaction. Since the FA used in the current study was defined as the low calcium material, the glassy phases (i.e., calcium-rich phase) in the GGBFS were first dissociated to calcium-rich components $\left(\mathrm{Ca}^{2+}\right)$ under the attack of $\mathrm{NH}$ solution. Then, $\mathrm{Ca}^{2+}$ would react with the active components of $\mathrm{SiO}_{2}$ and $\mathrm{Al}_{2} \mathrm{O}_{3}$ in the $\mathrm{FA}$ to form a large amount of hydrated products of C-S-H, C-A-S-H, and C-A-H gels. With 

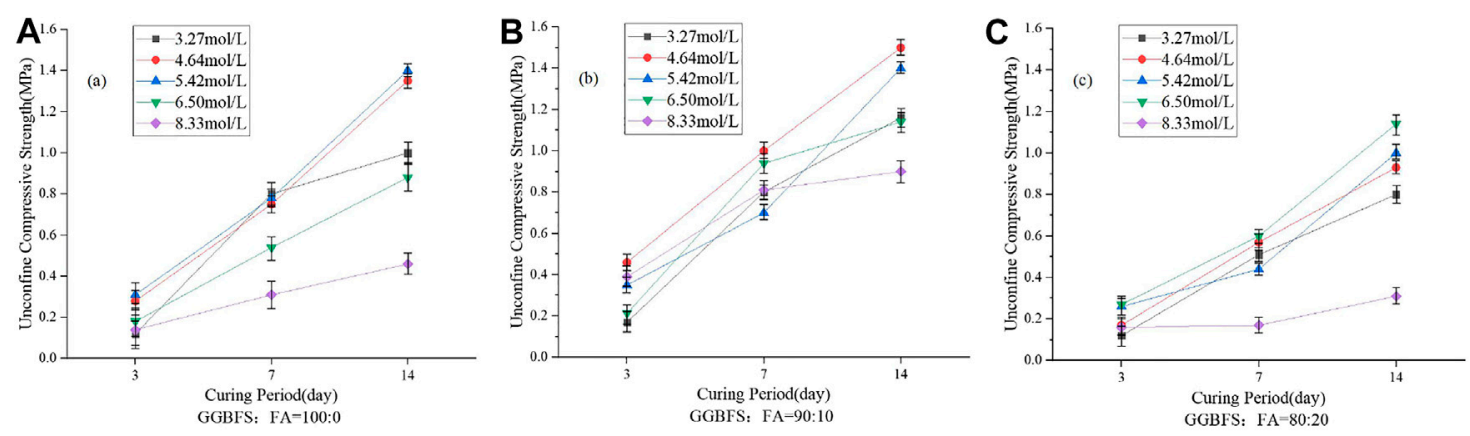

FIGURE 6 | UCS of soil stabilized by geopolymers with different molar concentrations of $\mathrm{NH}$ solution.

an increase in curing time, such hydration products overlapped each other, thereby increasing the strength of the one-part geopolymer-stabilized soft soil. Another aspect was that due to the spherical shape of FA, the FA played a role in rolling and lubricating in the binder-slurry, which would improve the fluidity of the binder-slurry, and made the binder-slurry spread more uniformly in the soft clay. This phenomenon indicated that the implementation of FA in raw materials performed the retardation of the initial setting time of binder-slurry. However, when the FA content in the precursor was beyond the certain amount, the silica-oxygen and aluminum-oxygen bonds in FA were rapidly broken and polycondensated to a three-dimensional aluminosilicate network structure of N-A-S-H, one kind of geopolymer in the low calcium system (Davidovits, 1989; Palomoa et al., 1999), under the activation of $\mathrm{NH}$ solution. It was found that the molecular structure of such an aluminosilicate gel was stable and cannot react with other active components in raw materials with an increase in curing time. Hence, the soil particle cannot be connected by such an aluminosilicate gel, resulting in the low UCS value of the stabilized soil. It can explain why the optimum ratio of GGBFS to FA in raw materials was $90 \%$ GGBFS and 10\% FA.

\section{Effect of Solid NH Content and Water-Binder Ratio}

Figure 6A reports the UCS values of the one-part geopolymerstabilized soil with $100 \%$ GGBFS in raw materials under varied molalities of $\mathrm{NH}$ solution. From the figure, it was clearly shown that when the molarity of $\mathrm{NH}$ solution was between 4.64 and $5.64 \mathrm{~mol} / \mathrm{L}$, the UCS values of stabilized soil reached a higher value of $1.4 \mathrm{MPa}$ at 14 days' curing time compared to that of the molarity of $\mathrm{NH}$ solution that is higher than $5.64 \mathrm{~mol} / \mathrm{L}$ or lower than $4.64 \mathrm{~mol} / \mathrm{L}$. This indicated that the higher or lower molarity of $\mathrm{NH}$ solution would not improve the mechanical property of soft clay significantly. This might be possible that the higher molarity of $\mathrm{NH}$ solution would cause the rapid reaction process in the geopolymer paste, resulting in shortening of initial setting time. During the preparation of the sample, it was observed that the geopolymer binder-slurry became a clump rapidly before mixing with soil, which might be the reason that geopolymerstabilized soil with $100 \%$ GGBFS under the higher molarity of $\mathrm{NH}$ solution presented the low compressive strength. At the same time, the lower molarity of $\mathrm{NH}$ solution would not effectively attack silicon-rich and calcium-rich components in the GGBFS, causing the low UCS values of the stabilized soil. Hence, for the one-part geopolymer-stabilized soil with the 100\% GGBFS in raw materials, the optimum molarity of $\mathrm{NH}$ solution was found to be in the range of $4.64 \mathrm{~mol} / \mathrm{L}-5.64 \mathrm{~mol} / \mathrm{L}$.

Figure 6B,C reports the UCS values of the one-part geopolymer-stabilized soil with GGBFS/FA ratios of $90-10 \%$ and $80-20 \%$ in Al-Si raw materials under various molarities of NH solution, respectively. From Figure 6B, it was found that when the molarity of NH solution was $4.64 \mathrm{~mol} / \mathrm{L}$, the UCS values of the stabilized soil with $90 \%$ GGBFS and 10\% FA achieved 1.5 MPa while for the stabilized soil with $80 \%$ GGBFS and $20 \%$ $\mathrm{FA}$, the optimum molarity of $\mathrm{NH}$ solution was found to be $6.50 \mathrm{~mol} / \mathrm{L}$. This is possible that the FA was an inert material, which was hardly activated by the low concentration of the $\mathrm{NH}$ solution. It can be postulated that the lower concentration of $\mathrm{NH}$ solution cannot effectively attack the aluminosilicate in the GGBFS and FA from the hydration gels, causing less improvement of the UCS values of the stabilized soil, while the higher concentration of the $\mathrm{NH}$ solution would induce the rapid releasing of calcium and silica ions in GGBFS and FA materials and reduce the setting time of geopolymer paste. Hence, after the binder-slurry was added into the soil, the soil particle cannot be effectively connected by the hydration gels from onepart geopolymers.

\section{Comparison with Cement-Stabilized Soft Clay}

Figure 7 reports the UCS values for the OPC with a grade of 42.5 stabilized soil and one-part geopolymer-stabilized soil with $90 \%$ GGBFS and $10 \% \mathrm{FA}$ at $4.64 \mathrm{~mol} / \mathrm{L} \mathrm{NH}$ solution. It was shown that at 7 days, the UCS values of the one-part geopolymer-stabilized soil and cement-stabilized soil were 1.0 and $0.8 \mathrm{MPa}$, respectively, while at 14 days, the compressive strength of geopolymerstabilized soil was much higher than that of cement-stabilized soil, which indicated that the GGBFS-FA-based geopolymer prepared by the one-part method in the current study can be used as an alternative soil stabilizer. Compared to the source of cement, the source of the geopolymer was the by-products with 


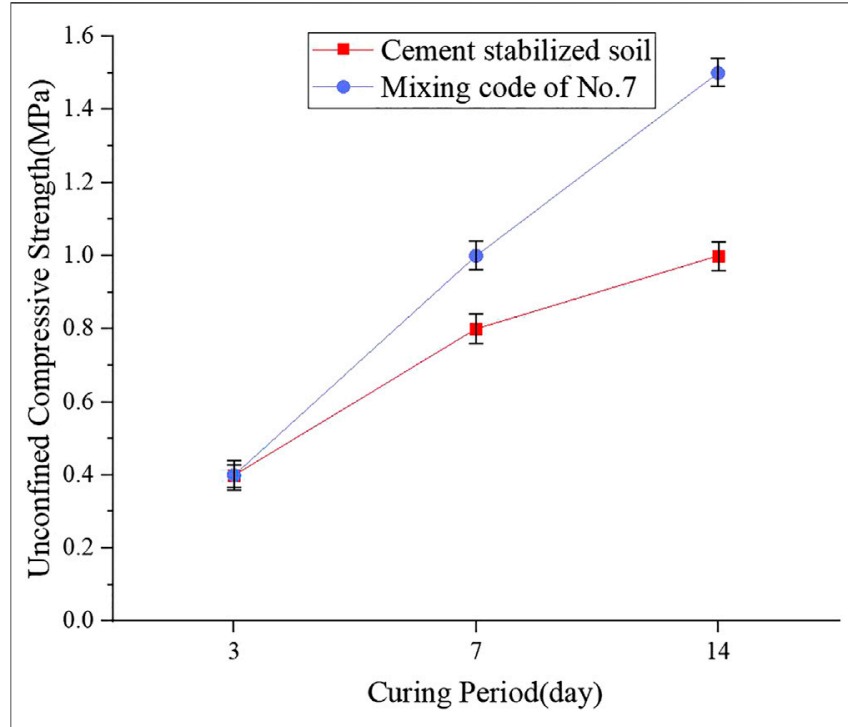

FIGURE 7 | UCS of soil stabilized by cement and mix \#7 geopolymers.

lower cost. Thus, the one-part GGBFS-FA-based geopolymer proposed in this study can be widely applied in the practice of ground improvement.

\section{Scanning Electron Microscope Analysis}

To study the microstructure of one-part geopolymers, SEM was used. From the above UCS values, it was observed that the onepart GGBFS-FA-based geopolymer-stabilized soft clay for each GGBFS/FA ratio had their corresponding optimum mixing proportion, that is, 1) for GGBFS: $\mathrm{FA}=100: 0, \mathrm{NH}$ activatorto-raw material ratio $=0.15$, water-to-binder ratio $=0.6$, and molarity of NH solution $=5.42 \mathrm{~mol} / \mathrm{L} ; 2)$ GGBFS: $\mathrm{FA}=90: 10, \mathrm{NH}$ activator-to-raw material ratio $=0.15$, water-to-binder ratio $=0.7$, and molarity of $\mathrm{NH}$ solution $=4.64 \mathrm{~mol} / \mathrm{L}$; and 3 ) GGBFS: $\mathrm{FA}=80: 20, \mathrm{NH}$ activator-to-raw material ratio $=0.15$, waterto-binder ratio $=0.5$, and molarity of $\mathrm{NH}$ solution $=6.50 \mathrm{~mol} / \mathrm{L}$. In order to further investigate the factors of GGBFS/FA ratio and molarities of $\mathrm{NH}$ solution on the development of the microstructure in geopolymer-stabilized soft clay at different curing times, the SEM image of soil samples with the above three mix proportions would be presented.
The morphology of hydration products in the one-part geopolymer-stabilized soft clay with $100 \%$ GGBFS to $0 \%$ FA at $5.42 \mathrm{~mol} / \mathrm{L} \mathrm{NH}$ solution is shown in Figure 8. It can be seen that there were amorphous calcium silicate $(\mathrm{C}-\mathrm{S}-\mathrm{H})$ gels in the stabilized soil, indicating that the early strength development of the stabilized soft clay was mainly due to the C-S-H gels. The C-S-H gel existed mainly in the form of network structure. At a curing time of 3 days, the stabilized soil samples produced few C-S-H gels. The microstructure of the sample was found to be loose. With an increase in curing time, more $\mathrm{C}-\mathrm{S}-\mathrm{H}$ gels were produced, and hence, the soil particles were tightly wrapped. At a curing time of 14 days, the hydration gel products were connected to each other, making the microstructure of the samples dense. Hence, the compressive strength of the stabilized soils increased significantly.

The SEM image of hydration products in the one-part geopolymer-stabilized soft clay with $90 \%$ GGBFS and $10 \%$ $\mathrm{FA}$ at $4.64 \mathrm{~mol} / \mathrm{L} \mathrm{NH}$ solution is shown in Figure 9. It was observed that at 3 days, the stabilized soil sample produced few $\mathrm{C}-\mathrm{S}-\mathrm{H}$ gels, inducing the loose state in the microstructure of the soil sample. At the same time, C-A-H and C-A-S-H gels were found in the formation of fibrous shape, confirming that the FA was involved in the reaction process. For the curing times of 7 and 14 days, the C-S-H and C-A-H gels overlapped and were found to form high compactness in the microstructure of the soil samples. It can be concluded that the implementation of FA in raw materials would react to produce hydrated gels to enhance the UCS values of the one-part geopolymerstabilized soil.

From Figure 10, the morphology of hydration products in the one-part geopolymer-stabilized soft clay with $80 \%$ GGBFS and $20 \% \mathrm{FA}$ at $6.50 \mathrm{~mol} / \mathrm{L} \mathrm{NH}$ solution is reported. It was observed that some C-S-H gels were produced and overlapped with each other with an increase in curing times. However, some $\mathrm{N}-\mathrm{A}-\mathrm{S}-\mathrm{H}$ gels with the formation of bulk (the chemical property of this material was analyzed by EDS in the following part) were observed at the early age of 3 days, which indicated the FA was involved in the geopolymerization process, in which the silica-oxygen and aluminum-oxygen bonds in FA were rapidly broken and polycondensated to an amorphous threedimensional aluminosilicate structure with the formation of the tetrahedron $\left[\mathrm{SiO}_{4}\right]$ and $\left[\mathrm{AlO}_{4}\right](\mathrm{N}-\mathrm{A}-\mathrm{S}-\mathrm{H})$. From the SEM

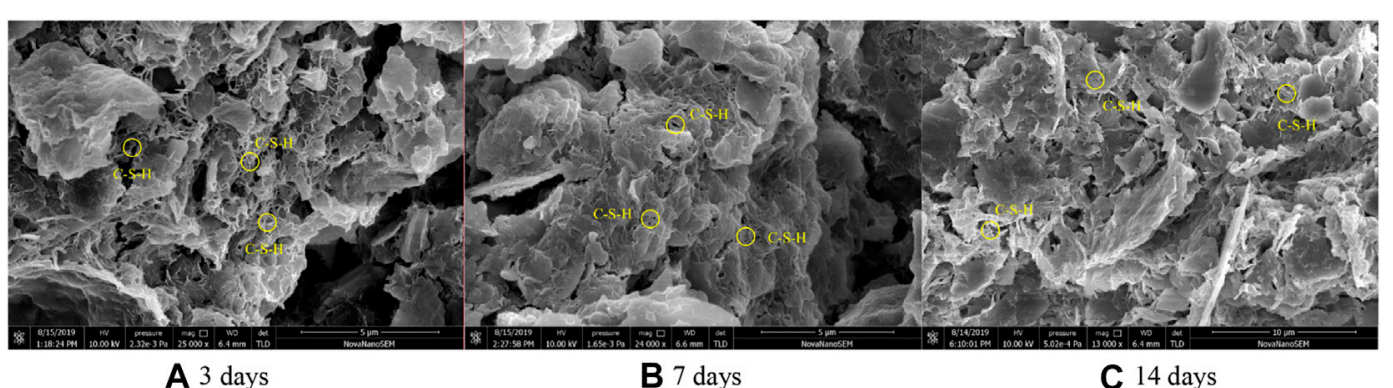
A 3 days
B 7 days
C 14 days

FIGURE 8 | SEM image of the one-part geopolymer-stabilized soft clay with 100\% GGBFS and 0\% FA at 5.42 mol/L NH solution: (A) 3 d; (B) 7 d; (C) 14 d. 


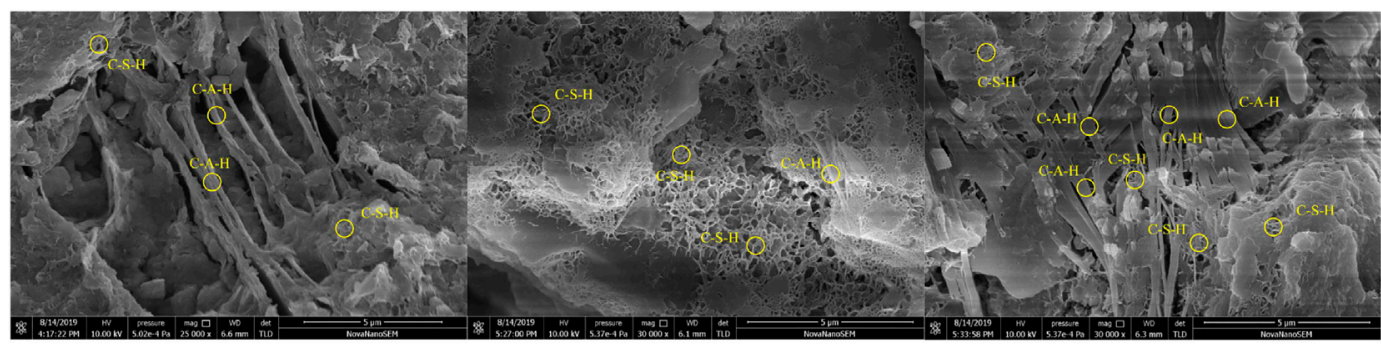
A 3 days
B 7 days
C 14 days

FIGURE 9 | SEM image of the one-part geopolymer-stabilized soft clay with 90\% GGBFS and 10\% FA at 4.64 mol/L NH solution: (A) 3 d; (B) 7 d; (C) 14 d.

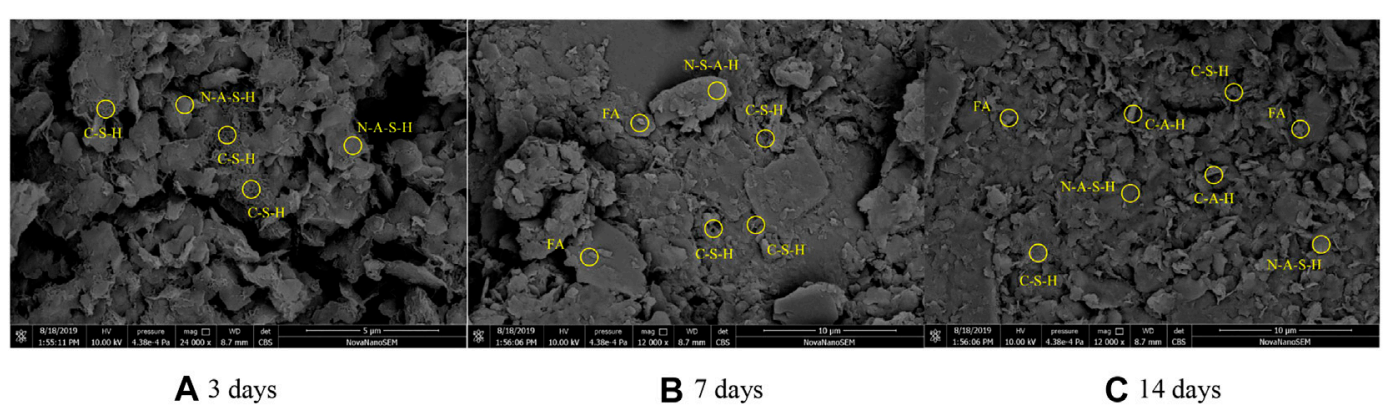

FIGURE 10 | SEM image of the one-part geopolymer-stabilized soft clay with $80 \%$ GGBFS and $20 \%$ FA at 6.50 mol/L NH solution: (A) 3 d; (B) 7 d; (C) 14 d.

image, some white dots were observed and determined to be unreacted FA materials (confirmed by the EDS results in the following part). It is clearly shown that even at the curing time of 14 days, many bulk parts and FA materials were observed and the microstructure of the soil sample was loose. This confirmed that FA was involved in the synthesis process of geopolymer to generate the N-A-S-H material, which cannot connect the soil particles effectively. The excessive amount of FA in raw materials cannot improve the strength of the stabilized soft clay significantly.

\section{Energy-Dispersive X-Ray Spectrometer Analysis}

Since the SEM image reported the morphology of hydration products in one-part geopolymer-stabilized soft clay, the EDS test was further conducted to analyze the chemical composition of the hydration products.

Figure 11 gives the EDS analysis of the selected areas within the one-part geopolymer-stabilized soft clay with $90 \%$ GGBFS and $10 \% \mathrm{FA}$ at $4.64 \mathrm{~mol} / \mathrm{L} \mathrm{NH}$ solution. The elemental composition of the selected areas is summarized in Table 4. The main elemental components of the cementitious material were composed of $\mathrm{Ca}, \mathrm{Si}$, and $\mathrm{Al}$, in which the atomic percentage of $\mathrm{Ca}, \mathrm{Si}$, and $\mathrm{Al}$ was found to be $8.64,16.81$, and 5.62, respectively. It can be concluded that this kind of cementitious material is $\mathrm{C}-\mathrm{S}-\mathrm{H}$ gel. From the SEM image (Figure 9), it can be observed that the cementitious material was abundant in GGBFS and FA-based geopolymer-stabilized soil, which is the main reason for the strength improvement of the one-part GGBFS and FA-based geopolymer-stabilized soil.

Figure 12 gives the EDS analysis of the selected areas within the one-part geopolymer-stabilized soft clay with 90\% GGBFS and $10 \%$ FA at $4.64 \mathrm{~mol} / \mathrm{L} \mathrm{NH}$ solution. The elemental composition of the selected areas is summarized in Table 5. Another major cementitious material existed in GGBFS and FAbased geopolymer-stabilized soil. The main elemental components of the cementitious material were composed of $\mathrm{Ca}, \mathrm{Si}$, and $\mathrm{Al}$, in which the atomic percentage of $\mathrm{Ca}, \mathrm{Si}$, and $\mathrm{Al}$ was found to be $16.64,10.10$, and 11.81 , respectively. These results demonstrated qualitative evidence for the formation of $\mathrm{C}-\mathrm{A}-\mathrm{H}$ or C-A-S-H gels in the soil samples. Hence, it can be concluded that such hydrated products were served to enhance the early UCS values of the one-part GGBFS and FA-based geopolymer-stabilized soil.

Figure 13 gives the EDS analysis of the selected areas within the geopolymer-stabilized soft clay with $80 \%$ GGBFS and $20 \%$ FA at $6.50 \mathrm{~mol} / \mathrm{L} \mathrm{NH}$ solution after a curing time of 14 days Table 6 reports the chemical composition of the selected areas. It should be noticed that the morphology of hydration products in the selected area had the bulk shape. From the figure, it is observed that the main components in the selected area were $\mathrm{Na}, \mathrm{Al}$, and $\mathrm{Si}$ with atomic percentages of $4.49,7.72$, and $18.44 \%$, respectively. This result indicated that under the action of $\mathrm{NH}$ activator with the high concentration, the silicon atom reacted with aluminum in the Al- 


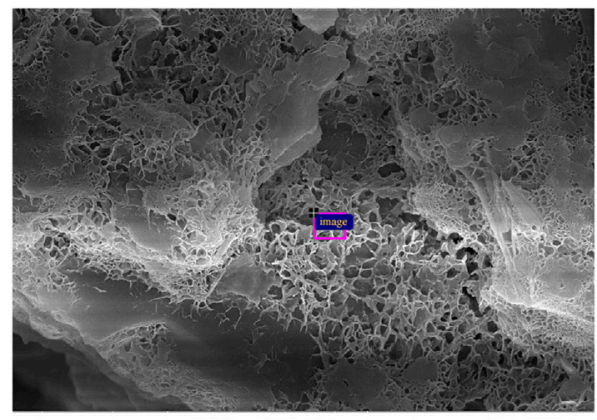

A Electronic image

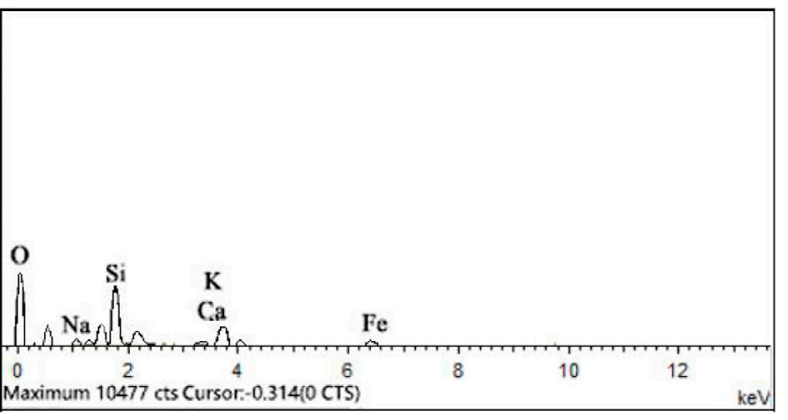

B Spectral diagram

FIGURE 11 | EDS of C-S-H from the one-part geopolymer-stabilized soil sample with 90\% GGBFS and 10\% FA at 4.64 mol/L NH solution: (A) Electronic image;

(B) Spectral diagram.

TABLE 4 | Elemental composition for selected areas in the one-part geopolymer-stabilized soil sample with 90\% GGBFS and 10\% FA at 4.64 mol/L NH solution for C-S-H.

\begin{tabular}{|c|c|c|c|c|}
\hline Element & Weight percentage & Atomic percentage & Compound percentage & Chemical formula \\
\hline $\mathrm{Na}$ & 2.23 & 2.27 & 3.01 & $\mathrm{Na}_{2} \mathrm{O}$ \\
\hline $\mathrm{Mg}$ & 1.43 & 1.37 & 2.37 & $\mathrm{MgO}$ \\
\hline Al & 6.49 & 5.62 & 12.27 & $\mathrm{Al}_{2} \mathrm{O}_{3}$ \\
\hline $\mathrm{Si}$ & 20.21 & 16.81 & 43.24 & $\mathrm{SiO}_{2}$ \\
\hline K & 2.16 & 1.29 & 2.61 & $\mathrm{~K}_{2} \mathrm{O}$ \\
\hline $\mathrm{Ca}$ & 14.52 & 8.46 & 20.32 & $\mathrm{CaO}$ \\
\hline $\mathrm{Fe}$ & 12.59 & 5.26 & 16.19 & $\mathrm{FeO}$ \\
\hline $\mathrm{O}$ & 40.36 & 58.92 & - & - \\
\hline Total & 100.00 & - & - & - \\
\hline
\end{tabular}

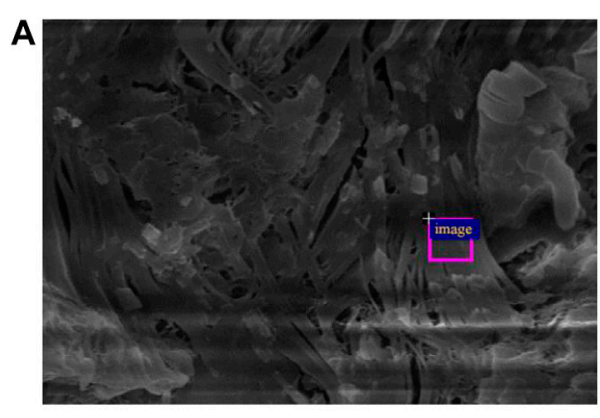

Electronic image

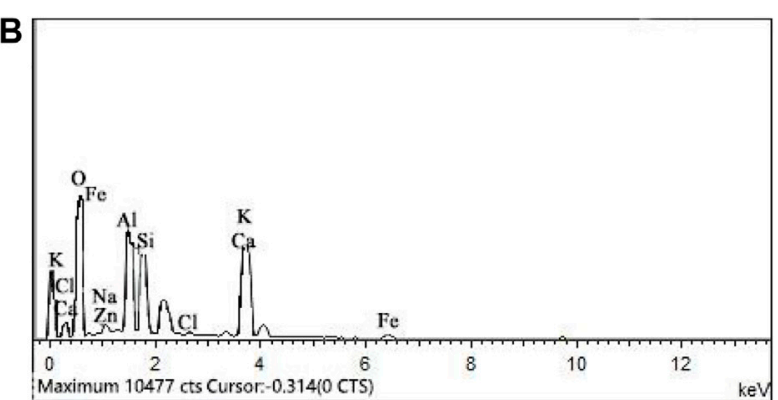

Spectral diagram

FIGURE 12 | EDS of C-A-H or C-A-S-H from the one-part geopolymer-stabilized soil sample with 90\% GGBFS and 10\% FA at 4.64 mol/L NH solution: (A) Electronic image; (B) Spectral diagram.

Si raw material, that is, the process of polycondensation occurred for the silicon and the aluminum element, and the released silicon-rich and aluminum-rich atoms reacted with water to form the geopolymer. However, such a product cannot connect the soil particles effectively and only served to fill the porosity of the soil, thus making little contribution to enhance the UCS values of the soil sample. Hence, it was confirmed that the excessive amount of FA would not significantly improve the strength of one-part geopolymer-stabilized soft clay.
Based on the SEM results, it was found that when the FA content in the Al-Si raw material was $10 \%$, there were few spherical particles, while when the FA content in the Al-Si raw material reached $20 \%$, a large number of spherical particles were found, as shown in Figure 10. Hence, the EDS analysis was conducted on this kind of spherical particle to obtain its elemental component, which is reported in Figure 14 and Table 7. From the table, it is found that the atomic percentage of $\mathrm{Si}$ and $\mathrm{Al}$ was 18.62 and 6.82, respectively, which confirmed that 
TABLE 5 | Elemental composition for selected areas in the one-part geopolymer-stabilized soil sample with 90\% GGBFS and 10\% FA at 4.64 mol/L NH solution for C-A-H or C-A-S-H.

\begin{tabular}{|c|c|c|c|c|}
\hline Element & Weight percentage & Atomic percentage & Compound percentage & Chemical formula \\
\hline $\mathrm{Na}$ & 1.17 & 1.20 & 1.58 & $\mathrm{Na}_{2} \mathrm{O}$ \\
\hline Al & 13.50 & 11.81 & 25.51 & $\mathrm{Al}_{2} \mathrm{O}_{3}$ \\
\hline $\mathrm{Si}$ & 12.02 & 10.10 & 25.72 & $\mathrm{SiO}_{2}$ \\
\hline $\mathrm{Cl}$ & 0.83 & 0.56 & 0.00 & - \\
\hline K & 1.07 & 0.64 & 1.29 & $\mathrm{~K}_{2} \mathrm{O}$ \\
\hline $\mathrm{Ca}$ & 28.25 & 16.64 & 39.53 & $\mathrm{CaO}$ \\
\hline $\mathrm{Fe}$ & 3.65 & 1.54 & 4.69 & $\mathrm{FeO}$ \\
\hline $\mathrm{Zn}$ & 0.68 & 0.25 & 0.85 & $\mathrm{ZnO}$ \\
\hline $\mathrm{O}$ & 38.82 & 57.26 & - & - \\
\hline Total & 100.00 & - & - & - \\
\hline
\end{tabular}

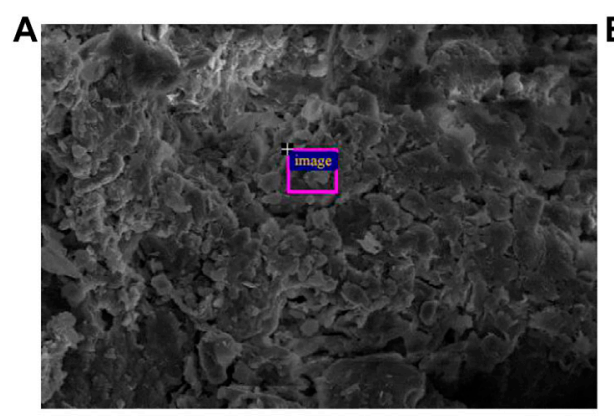

Electronic image

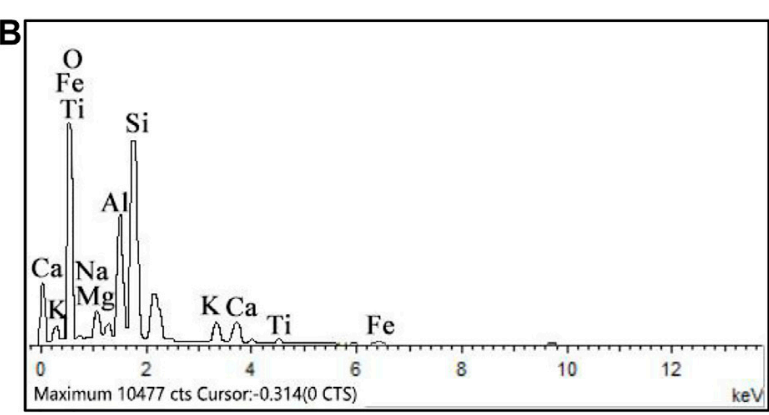

Spectral diagram

FIGURE 13 | EDS of N-A-S-H from stabilized soft clay with 80\% GGBFS and 20\% FA at 6.50 mol/L NH solution: (A) Electronic image; (B) Spectral diagram.

TABLE 6 | Elemental composition for selected areas in the one-part geopolymer-stabilized soil sample with 80\% GGBFS and 20\% FA at 6.50 mol/L NH solution for N-A-S-H.

\begin{tabular}{|c|c|c|c|c|}
\hline Element & Weight percentage & Atomic percentage & Compound percentage & Chemical formula \\
\hline $\mathrm{Na}$ & 4.83 & 4.49 & 6.51 & $\mathrm{Na}_{2} \mathrm{O}$ \\
\hline Mg & 4.56 & 4.01 & 7.57 & $\mathrm{MgO}$ \\
\hline Al & 9.76 & 7.72 & 18.44 & $\mathrm{Al}_{2} \mathrm{O}_{3}$ \\
\hline K & 2.02 & 1.10 & 2.44 & $\mathrm{~K}_{2} \mathrm{O}$ \\
\hline $\mathrm{Ca}$ & 4.95 & 2.64 & 6.92 & $\mathrm{CaO}$ \\
\hline $\mathrm{Ti}$ & 4.84 & 1.85 & 6.23 & $\mathrm{TiO}_{2}$ \\
\hline
\end{tabular}

FA partially involved in the geopolymer-stabilized soil. On the other hand, it can also prove that after certain amount of FA contents, further increasing amount of FA cannot help to increase the strength of geopolymer-stabilized soft soil.

\section{X-Ray Diffraction Analysis}

The XRD pattern of the one-part GGBFS-FA-based geopolymer-stabilized soft clay for 14 days curing time is given in Figures 15-17 in order to study the difference in each phase. It can be observed from the XRD pattern (Figure 2) of GGBFS, there was an amorphous phase in the raw material of GGBFS, while the XRD pattern (Figure 3) reported that there was a large amount of crystal material, i.e., quartz, silicone, mullite, and magnetite in the FA raw material. Under the action of alkaline activators, there was still a lot of quartz phase in the sample, implying that with an increase in FA content, the peak value of the main quartz phase increased continuously, as shown in Figures 15-17. Since the peak value represented the quality of crystal crystallization, it can then be concluded that the FA might not react completely in the stabilized soil. Combined with the UCS results of the one-part GGBFS-FA-based geopolymer-stabilized soft clay, it is shown that further increasing FA content would decrease the UCS of the stabilized soft soil. Hence, it can be explained that the FA was not the main component to produce the gels in the 


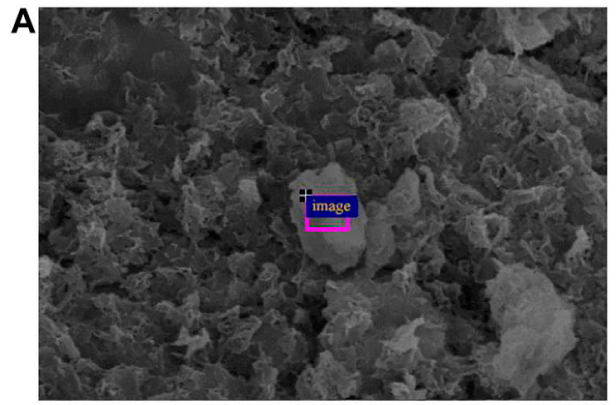

Electronic image

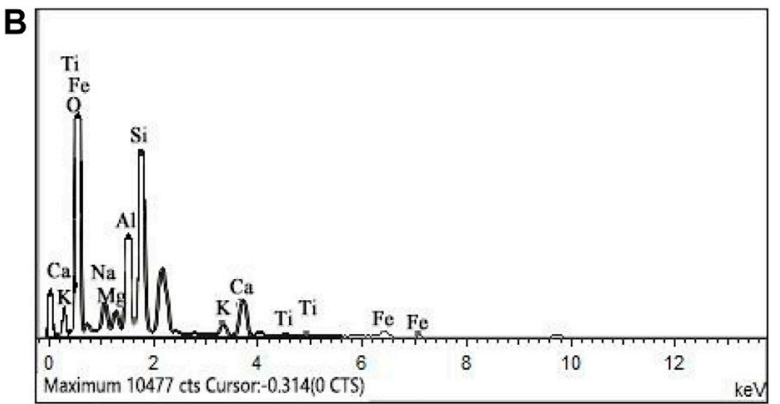

Spectral diagram

FIGURE 14 |EDS of FA from the selected area in the sample with 80\% GGBFS and 20\% FA at 6.50 mol/L NH solution: (A) Electronic image; (B) Spectral diagram.

TABLE 7 | Elemental composition for selected areas in the one-part geopolymer-stabilized soil sample with 80\% GGBFS and 20\% FA at 6.50 mol/L NH solution for FA.

\begin{tabular}{|c|c|c|c|c|}
\hline Element & Weight percentage & Atomic percentage & Compound percentage & Chemical formula \\
\hline $\mathrm{Na}$ & 1.18 & 1.15 & 1.59 & $\mathrm{Na}_{2} \mathrm{O}$ \\
\hline $\mathrm{Mg}$ & 4.63 & 4.26 & 7.68 & $\mathrm{MgO}$ \\
\hline $\mathrm{Al}$ & 8.23 & 6.82 & 15.55 & $\mathrm{Al}_{2} \mathrm{O}_{3}$ \\
\hline K & 4.21 & 2.41 & 5.08 & $\mathrm{~K}_{2} \mathrm{O}$ \\
\hline $\mathrm{Ca}$ & 2.18 & 1.21 & 3.04 & $\mathrm{CaO}$ \\
\hline $\mathrm{Ti}$ & 0.72 & 0.34 & 1.21 & $\mathrm{TiO}_{2}$ \\
\hline Total & 100.00 & - & - & - \\
\hline
\end{tabular}

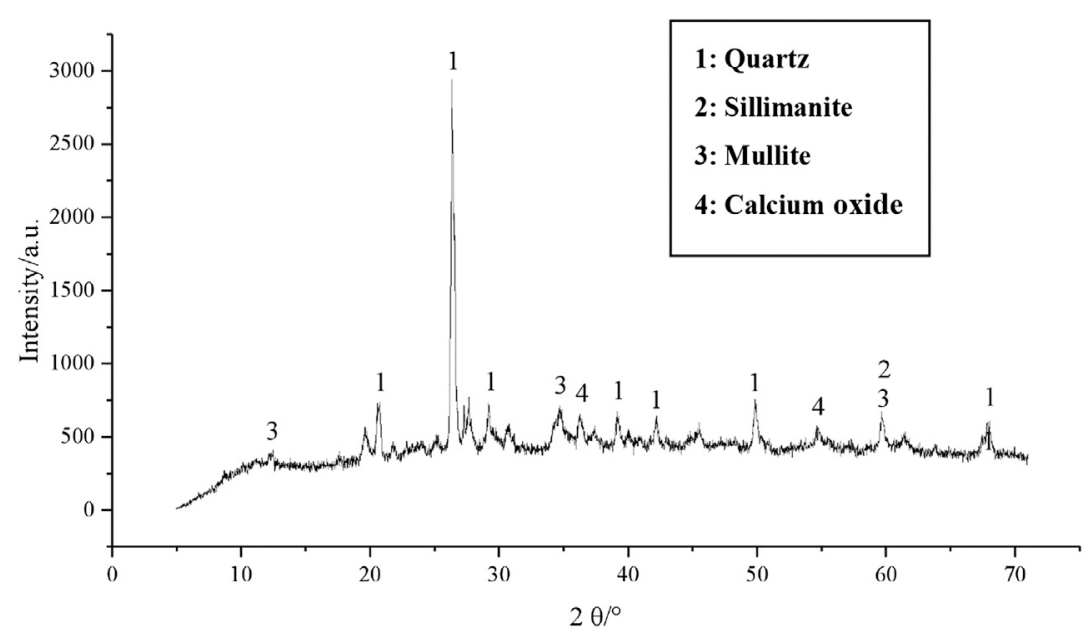

FIGURE 15 | XRD pattern of the one-part geopolymer-stabilized soft clay with 100\% GGBFS and 0\% FA at 5.42 mol/L NH solution for 14 days.

reaction process of GGBFS-FA-based geopolymer. On the contrary, it can indirectly demonstrate that GGBFS was the main component to produce the gels in the reaction process of GGBFS-FA-based geopolymer and then enhance the compressive strength of the stabilized soft clay, which was consistent with that observed in SEM results.

\section{CONCLUSION}

This paper studied the early strength development of the one-part GGBFS-FA-based geopolymer-stabilized soft clay. The effects of the GGBFS/FA ratio in the precursor, the ratio of $\mathrm{NH}$ activator to precursor, and the water-binder ratio on the strength 


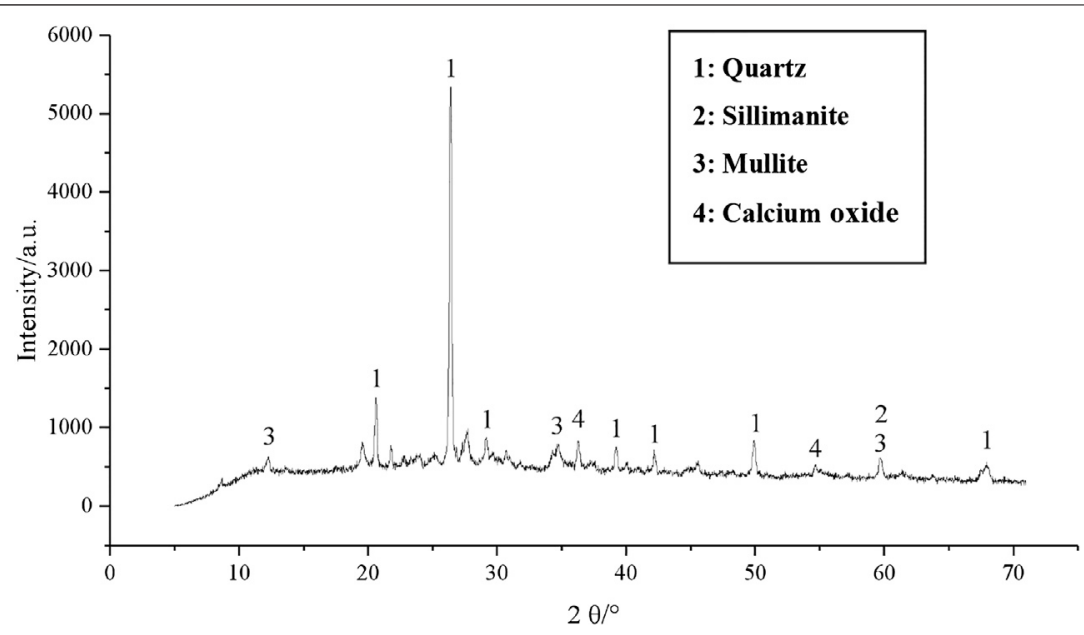

FIGURE 16 | XRD pattern of the one-part geopolymer-stabilized soft clay with $90 \%$ GGBFS and $10 \%$ FA at 4.64 mol/L NH solution for 14 days.

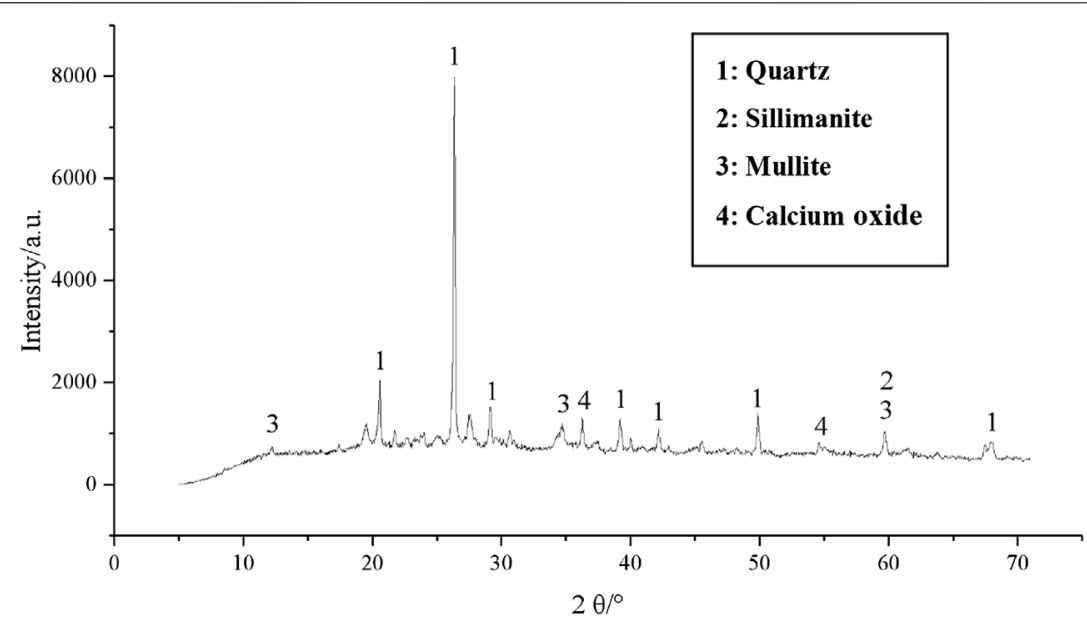

FIGURE 17 | XRD pattern of the one-part geopolymer-stabilized soft clay with $80 \%$ GGBFS and $20 \%$ FA at 6.50 mol/L NH solution for 14 days.

development and microstructure of stabilized soft clay were investigated via the UCS, SEM, XRD, and EDS test. The following conclusions can be drawn:

(1) In the one-part GGBFS-FA-based geopolymer-stabilized soft clay, the main hydration phase was the amorphous C-S-H gel, which can be effectively activated by the solid $\mathrm{NH}$ in one-part geopolymers. The reactive minor phases in one-part geopolymers consisted of C-A-H and C-A-S-H gels, which were the reaction products from the FA in raw materials. The occurrence of the C-S-H, C-A-H, or C-A-S$\mathrm{H}$ gel would overlap each other with an increase in the curing time and connect the soil particle to achieve high compactness in the microstructure of stabilized soil.

(2) During the hydration process, one function of the FA was used as a lubricant and water reducer, increasing the fluidity and uniformity of the binder-slurry, another function was providing the active $\mathrm{SiO}_{2}$ and $\mathrm{Al}_{2} \mathrm{O}_{3}$ components for the hydration reaction. In this paper, the best mixing proportion of the one-part GGBFS and FA-based geopolymer-stabilized soil was found to be $90 \%$ GGBFS and $10 \%$ FA in raw materials, solid $\mathrm{NH}$ activatorto-raw material ratio of 0.15 , and water-binder ratio of 0.7 , in which the UCS values reached $1.5 \mathrm{MPa}$ at 14 days' curing time.

(3) When the content of the FA in raw materials exceeded certain amount, increasing the FA content would perform negative impact on the early UCS values of the stabilized soil. The main reason was that the $\mathrm{Si}-\mathrm{O}$ $\mathrm{Si}$ and $\mathrm{Al}-\mathrm{O}-\mathrm{Al}$ bonds in the FA material were broken and rapidly polycondensated to form an amorphous aluminosilicate material (N-A-S-H). Such a reacted structure was very stable and cannot induce a secondary reaction between the soil particles, and it 
only served to fill the porosity in the soil. At the same time, the content of solid $\mathrm{NH}$ activator and water-binder ratio would determine the concentration of the $\mathrm{NH}$ solution, which influenced the reaction rate in the one-part geopolymer paste. For the one-part geopolymer-stabilized soil with different GGBFS/FA ratios, the optimum molarity of the $\mathrm{NH}$ solution varied to achieve the better UCS values of the stabilized soil.

(4) This paper adopted one-part technology to prepare the GGBFS-FA-based geopolymer soil stabilizer. Based on the UCS values of the stabilized soil, it was found that the UCS values of the one-part geopolymer-stabilized soil were much higher than those of cement-stabilized soil at the curing period of 14 days. This confirmed the feasibility that the onepart GGBFS and FA-based geopolymer can be used as an alternative binder to OPC in the practice of ground improvement.

\section{REFERENCES}

Bakharev, T., Sanjayan, J. G., and Cheng, Y.-B. (1999). Alkali activation of Australian slag cements. Cem. Concr. Res. 29 (1), 113-120. doi:10.1016/ s0008-8846(98)00170-7

Bakharev, T., Sanjayan, J. G., and Cheng, Y.-B. (2001a). Resistance of alkaliactivated slag concrete to alkali-aggregate reaction. Cem. Concr. Res. 31 (2), 331-334. doi:10.1016/s0008-8846(00)00483-x

Bakharev, T., Sanjayan, J. G., and Cheng, Y.-B. (2001b). Resistance of alkaliactivated slag concrete to carbonation. Cem. Concr. Res. 31 (9), 1277-1283. doi:10.1016/s0008-8846(01)00574-9

Bakharev, T. (2006). Thermal behaviour of geopolymers prepared using class F fly ash and elevated temperature curing. Cem. Concr. Res. 36 (6), 1134-1147. doi:10.1016/j.cemconres.2006.03.022

Bondar, D., Basheer, M., and Nanukuttan, S. (2019). Suitability of alkali activated slag/fly ash (AA-GGBS/FA) concretes for chloride environments: characterisation based on mix design and compliance testing. Constr. Build. Mater. 216 (20), 612-621. doi:10.1016/j.conbuildmat.2019.05.043

Chew, S. H., Kamruzzaman, A. H. M., and Lee, F. H. (2004). Physicochemical and engineering behavior of cement treated clays. J. Geotech. Geoenviron. Eng. 130 (7), 696-706. doi:10.1061/(asce)1090-0241(2004)130:7(696)

Chindaprasirt, P., De Silva, P., Sagoe-Crentsil, K., and Hanjitsuwan, S. (2012). Effect of $\mathrm{SiO}_{2}$ and $\mathrm{Al}_{2} \mathrm{O}_{3}$ on the setting and hardening of high calcium fly ashbased geopolymer systems. J. Mater. Sci. 47 (12), 4876-4883. doi:10.1007/ s10853-012-6353-y

Chinkulkijniwat, A., Suddeepong, A., and Horpibulsuk, S. (2012). Field strength development of repaired pavement using the recycling technique. Q. J. Eng. Geol. Hydrogeol. 45 (2), 221-229. doi:10.1144/1470-9236/11-031

Cristelo, N., Glendinning, S., and Teixeira Pinto, A. (2011). Deep soft soil improvement by alkaline activation. Proc. Inst. Civil Eng. - Ground Improvement 164 (2), 73-82. doi:10.1680/grim.900032

Davidovits, J. (1991). Geopolymers. J. Therm. Anal. 37, 1633-1656. doi:10.1007/ bf01912193

Davidovits, J. (1989). Geopolymers and geopolymeric materials. J. Therm. Anal. 35 (2), 429-441. doi:10.1007/bf01904446

Du, Y.-J., Wei, M.-L., Jin, F., and Liu, Z.-B. (2013). Stress-strain relation and strength characteristics of cement treated zinc-contaminated clay. Eng. Geol. 167 (17), 20-26. doi:10.1016/j.enggeo.2013.10.005

Duxson, P., Fernández-Jiménez, A., Provis, J. L., Lukey, G. C., Palomo, A., and Van Deventer, J. S. J. (2007). Geopolymer technology: the current state of the art. J. Mater. Sci. 42 (9), 2917-2933. doi:10.1007/s10853-0060637-z

\section{DATA AVAILABILITY STATEMENT}

The raw data supporting the conclusions of this article will be made available by the authors, without undue reservation.

\section{AUTHOR CONTRIBUTIONS}

The XZ made contributions to the experimental work and language writings. The JW has proposed the idea and innovation points of the present work.

\section{ACKNOWLEDGMENTS}

Grateful acknowledgment is made to the National Natural Science Foundation (no. 52078288) to support this project. The assistance of Mr. Xiao Xin from the Yancheng Institute of Technology for conducting the SEM and EDS analysis is appreciated.

Duxson, P., and Provis, J. L. (2008). Designing precursors for geopolymer cements. J. Am. Ceram. Soc. 91 (12), 3864-3869. doi:10.1111/j.1551-2916.2008.02787.x

Glukhovsky, V., Rostovskaja, G., and Rumyna, G. (1980). "High strength slagalkline cements," in Proceeding of the 7th international congress on the chemistry of cement (Paris, France: Elsevier), 164-168.

Gluth, G. J. G., Lehmann, C., Rübner, K., and Kühne, H.-C. (2013). Geopolymerization of a silica residue from waste treatment of chlorosilane production. Mater. Struct. 46 (8), 1291-1298. doi:10.1617/s11527-012-9972-5

Horpibulsuk, S., Katkan, W., Sirilerdwattana, W., and Rachan, R. (2006). Strength development in cement stabilized low plasticity and coarse grained soils: laboratory and field study. Soils Found. 46 (3), 351-366.

Huntzinger, D. N., and Eatmon, T. D. (2009). A life-cycle assessment of Portland cement manufacturing: comparing the traditional process with alternative technologies. J. Clean. Prod. 17 (7), 668-675. doi:10.1016/j.jclepro.2008.04.007

Itthikorn, P., Suksun, H., Runglawan, R., Arul, A., Shen, S. L., and Prinya, C. (2018). High calcium fly ash geopolymer stabilized lateritic soil and granulated blast furnace slag blends as a Pavement Base Material. J. Hazard. Mater. 341, 257-267.

Kang, G., Tsuchida, T., and Athapaththu, A. M. R. G. (2016). Engineering behavior of cement-treated marine dredged clay during early and later stages of curing. Eng. Geol. 209, 163-174. doi:10.1016/j.enggeo.2016.05.008

Keshawarz, M. S., and Dutta, U. (1993). Stabilization of south Texas soils with fly ash. in Fly ash for soil improvement 36, New York, NY United States: ASCE Geotechnical Special Publication. 10017-2398.

Kim, M. S., Jun, Y., Lee, C., and Oh, J. E. (2013). Use of $\mathrm{CaO}$ as an activator for producing a price-competitive non-cement structural binder using ground granulated blast furnace slag. Cem. Concr. Res. 54, 208-214. doi:10.1016/j. cemconres.2013.09.011

Ma, C., Chen, B., and Chen, L. (2018). Experimental feasibility research on a highefficiency cement-based clay stabilizer. KSCE J. Civ Eng. 22 (1), 62-72. doi:10. 1007/s12205-017-0782-8

Nematollahi, B., Sanjayan, J., Qiu, J., and Yang, E.-H. (2017b). High ductile behavior of a polyethylene fiber-reinforced one-part geopolymer composite: a micromechanics-based investigation. Arch. Civil Mech. Eng. 17 (3), 555-563. doi:10.1016/j.acme.2016.12.005

Nematollahi, B., Sanjayan, J., Qiu, J., and Yang, E.-H. (2017a). Micromechanicsbased investigation of a sustainable ambient temperature cured one-part strain hardening geopolymer composite. Constr. Build. Mater. 131, 552-563. doi:10. 1016/j.conbuildmat.2016.11.117

Nematollahi, B., Sanjayan, J., and Shaikh, F. U. A. (2015). Synthesis of heat and ambient cured one-part geopolymer mixes with different grades of sodium silicate. Ceram. Int. 41 (4), 5696-5704. doi:10.1016/j.ceramint. 2014.12 .154 
Palomo, A., Grutzeck, M. W., and Blanco, M. T. (1999). Alkali-activated fly ashes. Cem. Concr. Res. 29 (8), 1323-1329. doi:10.1016/s0008-8846(98)00243-9

Peys, A., Rahier, H., and Pontikes, Y. (2016). Potassium-rich biomass ashes as activators in metakaolin-based inorganic polymers. Appl. Clay Sci. 119, 401-409. doi:10.1016/j.clay.2015.11.003

Provis, L., and John, L. (2014). Geopolymers and other alkali activated materials: why, how, and what?. Mater. Struct. 47 (1-2), 11-25. doi:10.1617/s11527-013-0211-5

Sturm, P., Gluth, G. J. G., Brouwers, H. J. H., and Kühne, H.-C. (2016a). Synthesizing one-part geopolymers from rice husk ash. Constr. Build. Mater. 124, 961-966. doi:10.1016/j.conbuildmat.2016.08.017

Sturm, P., Gluth, G. J. G., Simon, S., Brouwers, H. J. H., and Kühne, H.-C. (2016b). The effect of heat treatment on the mechanical and structural properties of onepart geopolymer-zeolite composites. Thermochim. Acta 635, 41-58. doi:10. 1016/j.tca.2016.04.015

Sturm, P., Greiser, S., Gluth, G. J. G., Jäger, C., and Brouwers, H. J. H. (2015). Degree of reaction and phase content of silica-based one-part geopolymers investigated using chemical and NMR spectroscopic methods. J. Mater. Sci. 50 (20), 6768-6778. doi:10.1007/s10853-015-9232-5

Taha, R., Al-Harthy, A., Al-Shamsi, K., and Al-Zubeidi, M. (2002). Cement stabilization of reclaimed asphalt pavement aggregate for road bases and subbases. J. Mater. Civ. Eng. 14 (3), 239-245. doi:10.1061/(asce)0899-1561(2002)14:3(239)
Venkatanarayanan, H. K., and Rangaraju, P. R. (2013). Material characterization studies on lowand high-carbon rice husk ash and their performance in portland cement mixtures. Adv. Civil Eng. Mater. 2, 266-287. doi:10.1520/ acem20120056

Wang, K.-t., Du, L.-q., Lv, X.-s., He, Y., and Cui, X.-m. (2017). Preparation of drying powder inorganic polymer cement based on alkali-activated slag technology. Powder Technol. 312, 204-209. doi:10.1016/j.powtec.2017.02.036

Zhang, M., Guo, H., El-Korchi, T., Zhang, G., and Tao, M. (2013). Experimental feasibility study of geopolymer as the next-generation soil stabilizer. Constr. Build. Mater. 47, 1468-1478. doi:10.1016/j.conbuildmat.2013.06.017

Conflict of Interest: The authors declare that the research was conducted in the absence of any commercial or financial relationships that could be construed as a potential conflict of interest.

Copyright $\odot 2021$ Zheng and $W u$. This is an open-access article distributed under the terms of the Creative Commons Attribution License (CC BY). The use, distribution or reproduction in other forums is permitted, provided the original author $(s)$ and the copyright owner(s) are credited and that the original publication in this journal is cited, in accordance with accepted academic practice. No use, distribution or reproduction is permitted which does not comply with these terms. 